\title{
CHARACTERISTICS AND VIRULENCE OF AEROMONAS HYDROPHILA ISOLATES FROM FRESHWATER FISH WITH EPIZOOTIC ULCERATIVE SYNDROME (EUS)
}

\author{
W. H. S. CHANDRAKANTHI', A. PATHIRATNE ${ }^{2 *}$, and G. S. WIDANAPATHIRANA ${ }^{1}$ \\ 'Department of Microbiology, University of Kelaniya, Kelaniya. \\ ${ }^{2}$ Department of Zoology, University of Kelaniya, Kelaniya
}

(Received: 14 January 1999 ; accepted: 11 February 2000)

\begin{abstract}
Characteristics and virulence of Aeromonas hydrophila isolates recovered from ulcerated freshwater fisb during the outbreaks of Epizootic Ulcerative Syndrome (EUS) that occurred in 1990-1992 in Sri Lanka were examined to find out whether the isolates could be categorized to a single virulent phenotypic group. Fifty three isolates of A. hydrophila recovered from ulcerated fish bejonging to 12 different species collected from 8 different tresh water habitats during the disease cutbreaks were tested for 82 characteristics and the overall similarity of isolates was determined by numerical taxonomic analysis. At the $96 \%$ similarity value, the isolates were grouped into seven phenons. Total number of isolates categorized under the phenons I, II, III, IV, V, VI, and VII were 18, 5, 9, 5, 9,4 and 3 respectively. Virulence screening tests of the isolates showed that $78 \%$ isolates classified under phenon I and all the isolates of phenon II were weakly virulent, $78 \%$ isolates of phenon III and all the isolates of phenon IV were moderately virulent, whereas $75 \%$ isolates of phenon VI and all the isolates of phenons $\mathrm{V}$ and VII were highly virulent. Antibiotic susceptibility tests showed that the isolates were resistant to ampicillin, rifampicin and trimethoprim but sensitive to chloramphenicol, gentamicin, kanamycin, nalidixic acid, nitrofurantoin, oxytetracyclin, streptomycin and tetracycline. Suscertibi? ty to erythromycin and sulphonamide was variable. Phenotypic variations and range of virulence exhibited by $\Lambda$. hiydrophila isolates recovered fiom uleerated fish collected from different hahitats in Sri Lanka during the outbreaks of EUS indicate that a single highly virulent phenotypic group of $A$. hiydrophila is not primarily associated with the disease.
\end{abstract}

Key words: Aeromonas hydrophila, antibiotic sensitivity, epizootic ulcerative syndrome (EUS), ulcerated fish, vinulence

\section{INTRODUCTION}

Epizootic Ulcerative Syndrome (EUS) characterised by severe ulcerations of the skin and muscles is a serious disease of freshwater and brackish water fisshes in Asia and Pacific. ${ }^{1 \cdot 2}$ EUS was first reported in Sri Lanka in late 1987. The disease caused heavy mortality in more than 20 species of freshwater and estuarine fish in the South Western Province. "Since then EUS has recurred in Sri Lanka. ${ }^{4-6}$ However the disease incidence appears to be lower than that in the initial years.

\footnotetext{
"Corresponding author"
} 
EUS seems to have a complex infectious aetiology. Improving the understanding of the complex aetiology of EUS would be useful to evolve preventive and control measures to minimize the occurrence of the disease. Bacteria, such as Aeromonas hydrophila and Vibrio anguillarum, the fungus, Aphanomyces and rhabdoviruses have been isolated from EUS affected fish. ${ }^{2-7}$ More recent studies indicate that the Oomycete fungus, Aphanomyces invadans is the necessary cause of EUS." However the importance cf hacteria in the pathogenesis of the disease can not be ruled out. ${ }^{8}$ Our previous bacterial investigation on EUS affected fish collected from various freshwater bodies in Sri Lanka showed that A. hydrophila was the predominant bacteria consistently isolated from EUS affected fish in Sri Lanka." In the present investigation, detailed characteristics of the A. hydrophila isolates recovered from ulcerated fish collected from different freshwater habitats in Sri Lanka during three outbreaks of EUS were tested to determine the overall similarity of the isolates by numerical taxonomic analysis. Virulence of the isolates was also screened to see whether all the isolates could be categorized to a single virulent strain. In addition, susceptibility of $A$. hydrophila isolates to different antimicrobial drugs was evaluated.

\section{METHODS AND MATERIALS}

Bacteria isolation and identification: Fish showing gross clinical signs of EUS were collected from eight freshwater bodies in the Western, North-Western, and Sabaragamuwa Provinces in Sri Lanka viz. Boralasgamuwa reservoir, Bemmulla canal, Hamilton canal, shallow streams near paddy fields at Kirindiwela and Agalawatte, Lunuwila reservoix, Mahawewa reservoir and Gurukoda Oya during three consecutive disease outbreaks that occurred in December 1990, December 1991- January 1992 and in December 1992. Samples were collected for bacteria as stated previously from muscle below the lesion and internal organs of twenty four ulcerated fish belonging to twelve different species: Anabas testudineus, Esomus danrica, Etroplus maculatus, Etroplus suratensis, Ophicephalus striatus, Puntius filamantosus, Puntius bimaculatus, Puntius sarana, Rasbora daniconius, Tor khudree, Trichogaster pectoralis, and Wallago attu. Samples were cultured on nutrient agar, or trypticase soy agar or Rimler-Shotts agar and incubated at 27-30 "C for $24-48$ h. The dominant isolates were purified and maintained on trypticase soy agar and nutrient agar. Of the total of 83 bacterial isolates recovered from EUS affected fish, 53 isolates were identified and later confirmed as A. hydrophila using the standard methods. ${ }^{10-12}$ The 53 isolates included 32 A. hydrophila isolates recovered from our previous bacteriological investigation. ${ }^{4}$ In the present study, a total of 82 characteristics including growth, morphological, physiological and biochemical characteristics of each of the 53 isolates were examined for taxonomic analysis, and similarity values(Sm) between the isolates were computed using the formula described by Sneath. ${ }^{13}$ 
$\mathrm{Sm}=\mathrm{N}_{\mathrm{s}} /\left(\mathrm{N}_{\mathrm{s}}+\mathrm{N}_{\mathrm{d}}\right) \times 100$, where $\mathrm{N}_{\mathrm{s}}$ was the number of similarities between isolates, $N_{d}$ was the number of dissimilar characters between the isolates. After similarity values were calculated pairwise, the data were arranged in a similarity matrix. The data were then transposed into a dendrogram and used as a basis for determining taxonomic arrangements in terms of numerical relationships for all the isolates of A. hydrophila.

Virulence screening: All the isolates of A. hydrophila recovered from EUS-affected fish were screened for virulence. The isolates were subcultured and resuspended in sterilized saline at $10^{\circ}$ colony forming units $/ \mathrm{ml}$. Healthy Etroplus suratensis (an EUS susceptible fish species) weighing 19-27g were injected intramuscularly with bacterial isolates at the region $1-1.5 \mathrm{~cm}$ below the anterior part of the dorsal fin at a dose of $0.05 \mathrm{ml}$, containing approximately $5 \times 10^{6}$ CFU per test fish. Control fish were injected with $0.05 \mathrm{ml}$ of sterilized saline. Ten fish were used for each group. The virulence of the isolates was categorized on the basis of development of lesions and percentage mortalities: $100 \%$ mortality within 24 h as highly virulent; over $50 \%$ mortality with a haemorrhagic lesion within $24-48$ h as moderately virulent; over $50 \%$ mortality with a haemorrhagic lesion after $48 \mathrm{~h}$ but within $120 \mathrm{~h}$ as weakly virulent; less than $50 \%$ mortality at $120 \mathrm{~h}$ without lesion development as avirulent. Freshly dead fish were isolated for $A$. hydrophila to satisfy Koch's postulates. Possible relationships between differtnt iochemical characteristics and the virulence levels of isolates were determined by pairwise cross correlation analysis. ${ }^{14}$

Antibiotic susceptibility tests: Thirteen antimicrobial drugs were evaluated for effectiveness against the A. hydrophila isolates using disk diffusion technique. ${ }^{15}$ The antimicrobial drugs used were ampicillin, chloramphenicol, erythromycin, gentamicin, kanamycin, nalidixic acid, nitrofurantoin, oxytetracyclin, rifampicin, streptomycin, sulphonamide, tetracycline and trimethoprim.

\section{RESULTS}

Profĩle of 53 isolates of $A$. hydrophila recovered from twenty four ulcerated fish including twelve different species are presented in Table 1 . The isolates were recovered from the muscular lesion, liver, kidney and spleen. Morphological, growth, physiological and biochemical characteristics followed for the identification of A. hydrophila are presented in Table 2. Most of the characteristics were consistent for all the isolates but variable results were obtained for 10 characteristics: hydrolysis of aesculin, utilization of citrate as sole source of carbon (Simmon's citrate), liquefaction of gelatine, production of $\mathrm{H}_{2} \mathrm{~S}$ from $2.5 \%$ peptone water, formation of indole from tryphtophan, methyl red reaction, formation of acetoin from glucose(Voges Proskauer test), production of reddish brown pigment on tyrosine agar and fermentation of L-arabinose and salicin. In general, the isolates recovered from lesions and internal organs of the same fish showed 


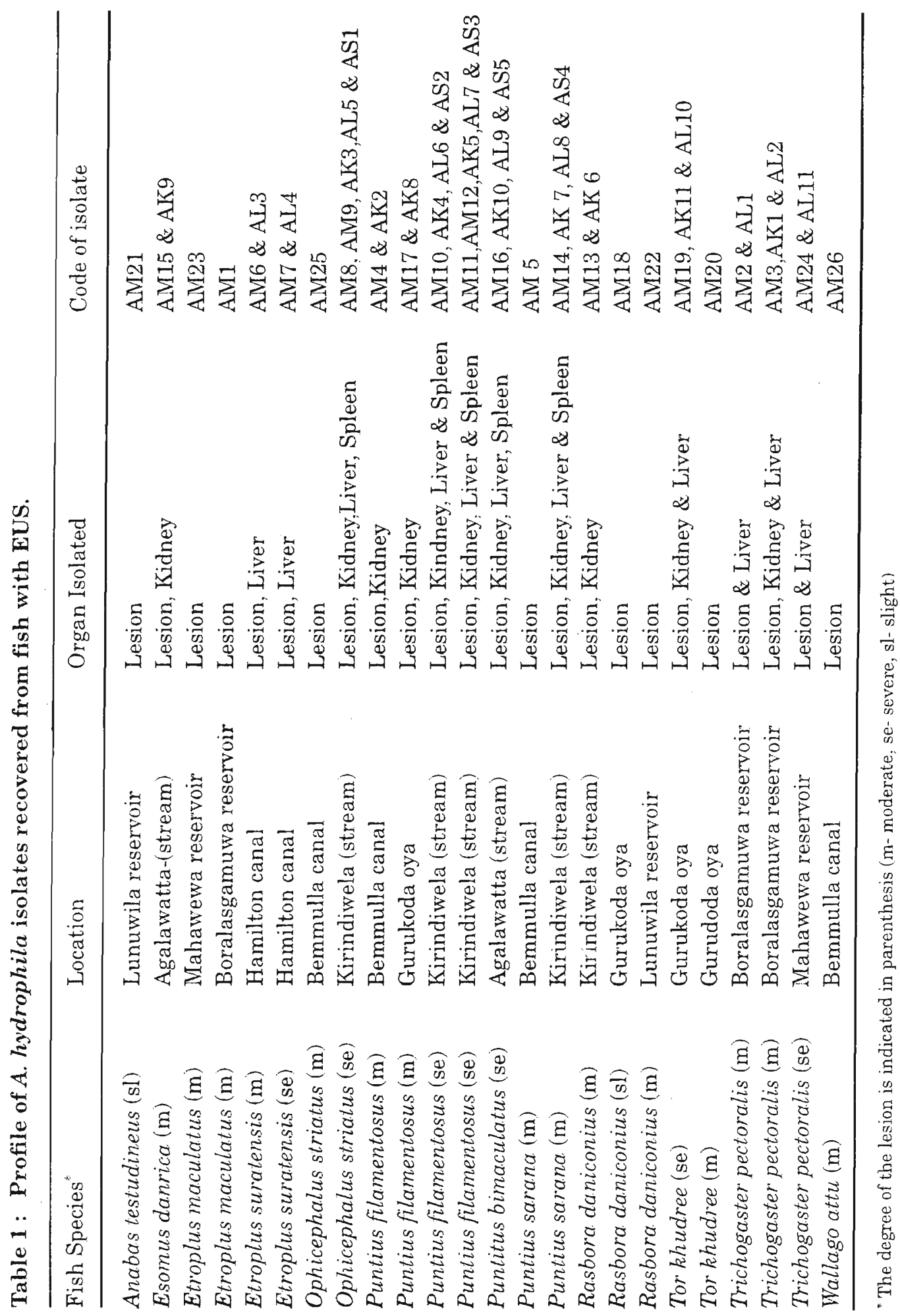


Table 2: Morphological, growth, physiological and biochemical characteristics of A. hydrophila isolates recovered from EUS affected fish

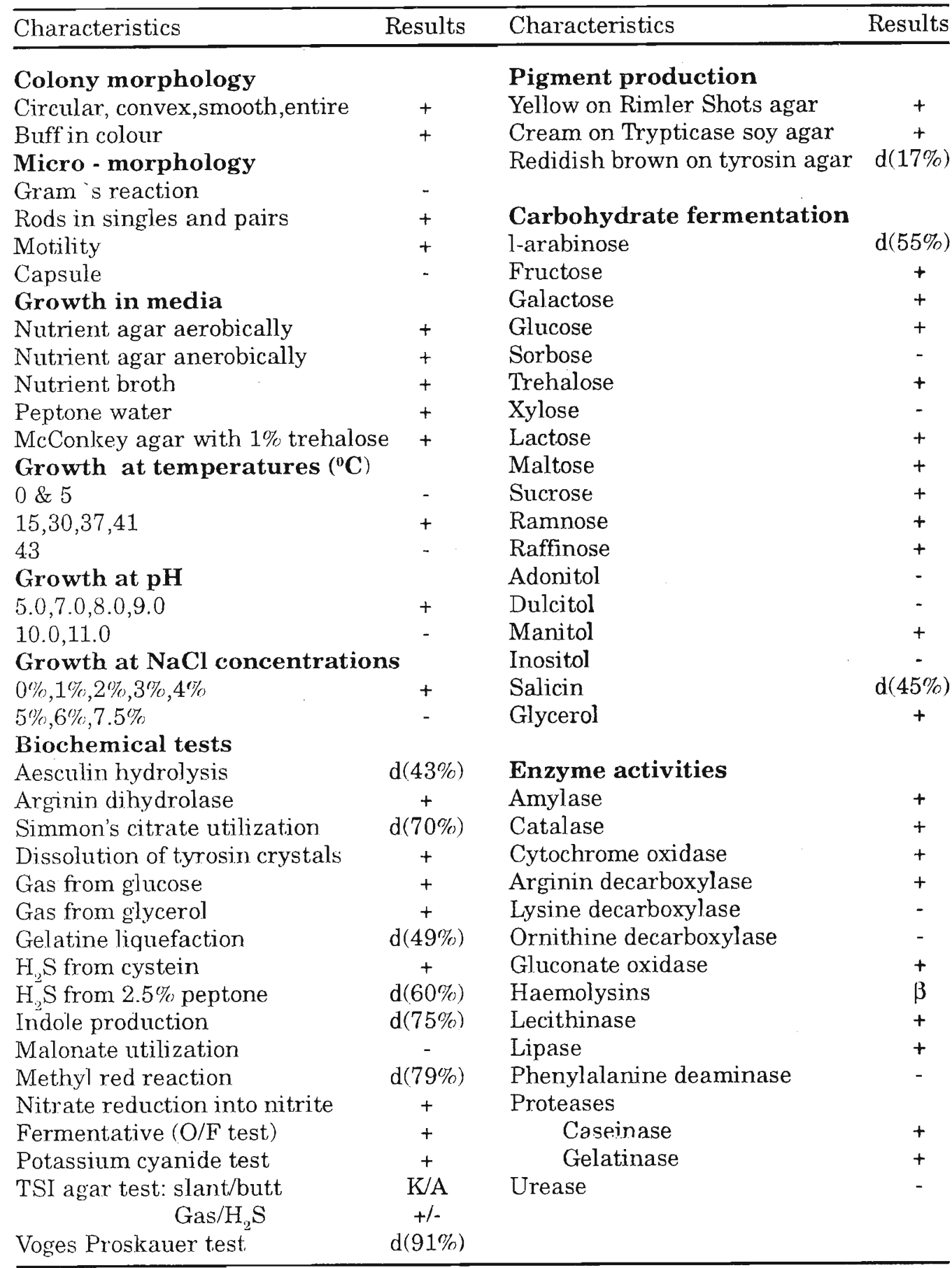

Total of 82 characteristics were tested for the total of 53 isolates. $+: 100 \%$ positive for the characteristic, - : $100 \%$ negative for the characteristic; $d$ : differs among isolates (\% positive), A-acid, K-alkaline, TSI trip]e sugratiron 
similar characteristics whereas variable characteristics were observed among the isolates of $A$. hydrophila recovered from the fish sampled from different locations. The diagrammatic representation of relationships of similarity matrices of the 53 isolates of A. hydrophila are given in Fig. 1. Based on the 10 variable characteristics of the 82 characteristics studied, the 53 isolates were classified into 7 phenons with mean similarities of more than $96 \%$ (Fig. 2). Percent similarity of the total of 53 isolates was between $88 \%-100 \%$.

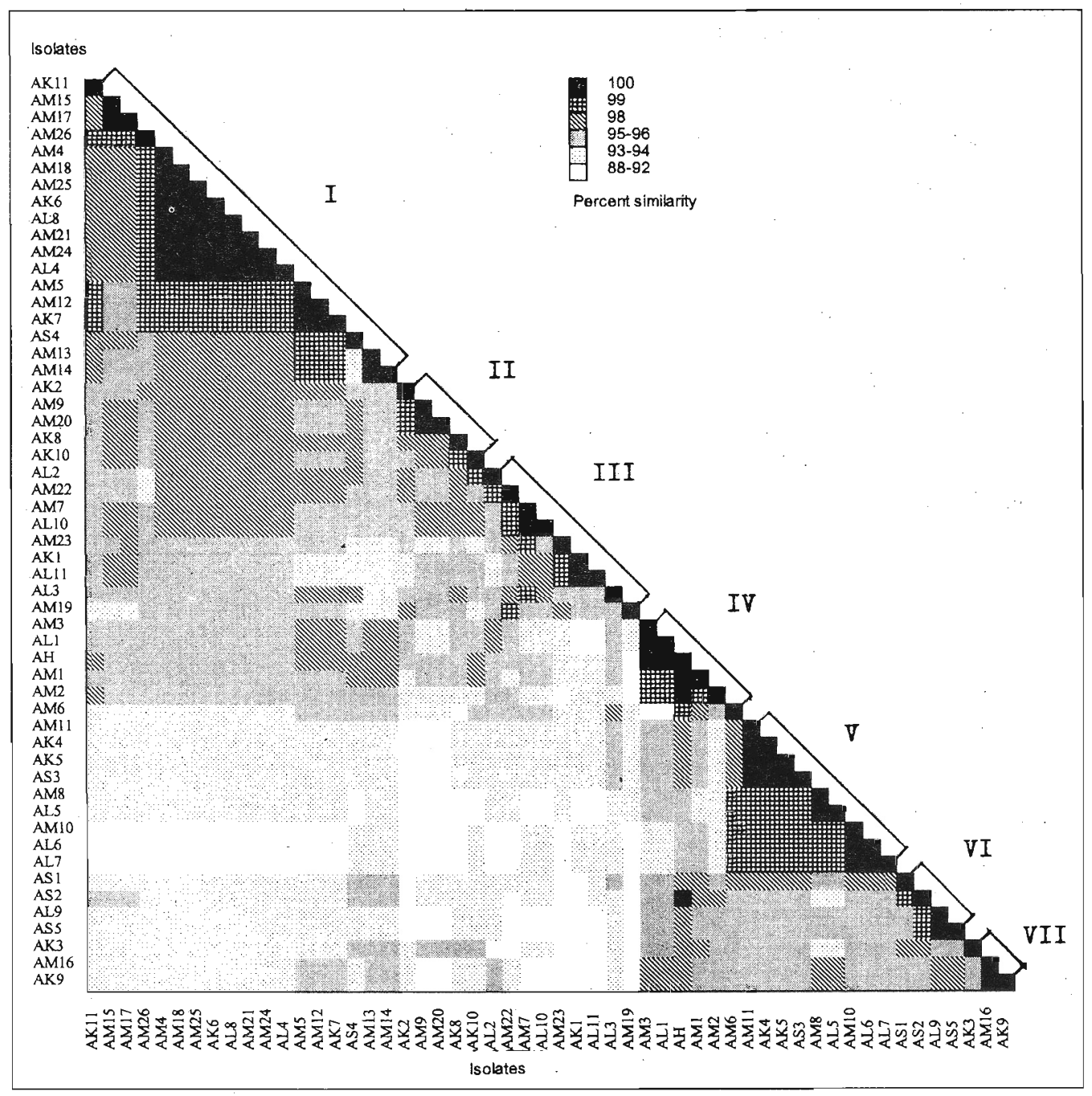

Figure 1: Similarity matrices for 53 isolates of Aeromonas hydrophila recovered from EUS affected fish.

AM1 -AIM26 : isolates recovered from lesion; AK1-AK11: isolates recovered from kidney; AL1-AL11: isolates recovered from liver, AS1-AS5: isolates recovered from spleen; AH: characteristics of A. hydrophila given in Bergey 's Manual ${ }^{12}$ 


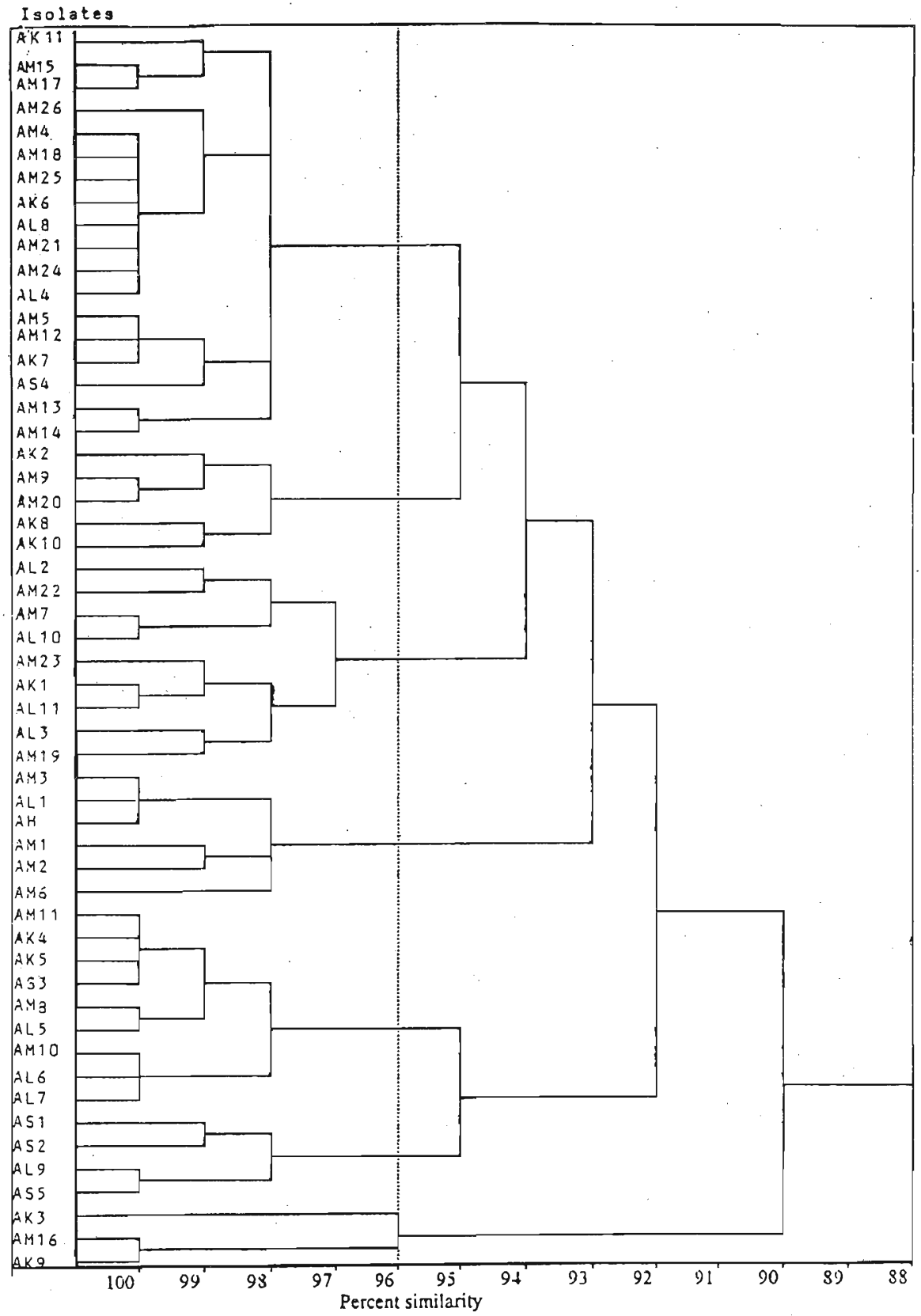

Figure 2: Dendrogram showing similarity relationships among the 53 isolates of Aeromonas hydrophila recovered from EUS affected fish. Seven phenons are evident above $96 \%$ phenon line.

AM1-AM26: Isolates recovered from lesion; AK1-AK11: isolates recovered from kidney; AL1-AL11: isolates recovered from liver, AS1-AS5: isolates recovered from spleen; $\mathrm{AH}$ : characteristics of $A$. hydrophila given in Bergey's Manual'12 
Inconsistent biochemical characteristics among phenons are presented in Table 3. Of the inconsistent characteristics found, four characteristics shown by all the isolates of phenon I were similar to the typical characteristics of $A$. hydrophila (utilization of citrate as sole source of carbon, $\mathrm{H}_{2} \mathrm{~S}$ production from peptone water, indole production, and VP test). However, the isolates were unable to ferment salicin. Only some of the isolates were able to hydrolyse aesculin and ferment arabinose. All the isolates classified under phenon II were unable to hydrolyse aesculin and ferment arabinose. All the isolates of phenon III showed only one characteristic typical to A. hydrophila, the positive reaction for Simmon's citrate test. The isolates of phenon IV were completely positive for the characteristics of typical $A$. hydrophila. The isolates grouped into the phenon V, VI and VII were completely positive for most of the characteristics of typical A. hydrophila. However, most of the isolates in phenon V, VI and VII produced reddish brown pigment in tyrosine agar, which is an atypical characteristic of A. hydrophila.

Table 3 : Inconsistent biochemical characteristics ${ }^{*}$ of $A$. hydrophila classified under seven phenons

\begin{tabular}{|c|c|c|c|c|c|c|c|}
\hline \multirow{2}{*}{$\begin{array}{l}\text { Characteristics } \\
\text { (No. of positive / total tested) }\end{array}$} & \multicolumn{7}{|c|}{ Phenon (Number of isolates) } \\
\hline & I & II & III & IV & $\mathrm{V}$ & $\mathrm{VI}$ & VII \\
\hline Aesculin hydrolysis $(23 / 53)$ & $2 / 18$ & - & - & + & + & + & + \\
\hline Simmon's citrate test $(37 / 53)$ & + & + & + & + & - & - & - \\
\hline Fermentation of L-arabinose (29/53) & $7 / 18$ & - & $1 / 9$ & + & + & + & + \\
\hline Fermentation of salicin $(24 / 53)$ & - & $1 / 5$ & $2 / 9$ & + & + & + & + \\
\hline Gelatine liquefaction $(26 / 53)$ & $3 / 18$ & $4 / 5$ & $5 / 9$ & $2 / 5$ & $7 / 9$ & + & $1 / 3$ \\
\hline $\mathrm{H}_{2} \mathrm{~S}$ from $2.5 \%$ peptone water $(32 / 53)$ & + & + & $1 / 9$ & $2 / 5$ & - & $3 / 4$ & + \\
\hline Indole in tryptophane $(40 / 53)$ & + & + & $5 / 9$ & + & - & + & + \\
\hline Methyl red test (42/53) & $14 / 18$ & + & $6 / 9$ & $4 / 5$ & + & $1 / 4$ & + \\
\hline $\begin{array}{l}\text { Reddish brown pigment }(9 / 53) \\
\text { in tyrosine agar }\end{array}$ & - & - & - & - & $5 / 9$ & $2 / 4$ & $2 / 3$ \\
\hline Voges Proskaner test $(48 / 53)$ & + & $2 / 5$ & 8,9 & + & + & + & $2 / 3$ \\
\hline
\end{tabular}

+ : $100 \%$ positive reaction; - : 100\% negative reaction, values in parentheses indicate number of isolates with positive reaction/total number of isolates grouped under the phenon.

The summary of the results of virulence screening among the isolates is shown in Table 4. Thirty six percent of the isolates (19/53) were highly virulent; $28 \%(15 / 53)$ were moderately virulent and $36 \%$ (19/53) were weakly virulent. Most of the isolates $(78 \%)$ in phenon I and all the isolates in phenon II were weakly virulent. Most of the moderately virulent isolates belonged to the phenon III and IV. Majority of the isolates classified as highly virulent came from phenon V, VI and 
VII. Most virulent isolates were recovered from severely infected fish. Some inconsistent biochemical characteristics of the isolates were significantly correlated with their virulence potential (Table 5). The statistical analysis indicates that the virulence potential is positively correlated with hydrolysis of aesculin, and fermentation of salicin and negatively correlated with the indole production $(\mathrm{p}<0.05)$.

Table 4: Virulence potential of $A$. hydrophila isolates recovered from EUS affected fish

\begin{tabular}{lccc}
\hline Phenon (total isolates) & \multicolumn{3}{c}{ Number of isolates } \\
\cline { 2 - 4 } & $\begin{array}{c}\text { Weakly } \\
\text { virulent }\end{array}$ & Moderately virulent & $\begin{array}{c}\text { Highly } \\
\text { virulent }\end{array}$ \\
\hline I (18) & 14 & 2 & 2 \\
II (5) & 5 & 0 & 0 \\
III (9) & 0 & 7 & 2 \\
IV (5) & 0 & 5 & 0 \\
V (9) & 0 & 0 & 9 \\
VI (4) & 0 & 1 & 3 \\
VII (3) & 0 & 0 & 3 \\
\hline
\end{tabular}

Antibiotic susceptibility tests with different standard concentrations of antimicrobial drugs (Table 6) show that the jsolates were $100 \%$ sensitive to chloramphenicol, gentamicin, kanamycin, nalidixic acid, nitrofurantoin, oxytetracyclin, streptomycin and tetracycline. The isolates were $100 \%$ resistant to ampicillin, rifampicine and trimethoprim. Variable sensitivities were obtained for erythromycin and sulphonamide.

\section{DISCUSSION}

A. hydrophila is an opportunistic bacterium, which produces diseases under stress conditions, often in association with other microorganisms. ${ }^{16}$ There is a marked heterogeneity within the species description of $A$. hydrophila. ${ }^{12.16,17}$ Numerical taxonomic analysis on strains of Aeromoncs has been carried out to separate them into different genospecies. ${ }^{17 .}$. Previously it was noted that three characteristics of the total of 46 characteristics tested were inconsistent for the A. hydrophila isolates recovered from EUS affected fish in Sri Lanka. ${ }^{4}$ In the present study, detailed analysis of characteristics of $A$. hydrophila isolates recovered from EUS affected fish collected from different freshwater habitats in Sri Lanka indicated that 10 characteristics of the total of 82 characteristics studied were inconsistent. Based on the inconsistent characteristics, the isolates were grouped into seven phenons 
Table 5: Relationship between inconsistent biochemical characteristics and virulence potential of Aeromonas hydrophila isolates recovered from EUS affected fish

\begin{tabular}{|c|c|c|c|c|}
\hline \multirow{2}{*}{$\begin{array}{l}\text { Biochemical } \\
\text { characteristics }\end{array}$} & \multicolumn{3}{|c|}{ mber of positives/Total number of isolates } & \multirow[t]{2}{*}{$\overline{R^{2 *}}$} \\
\hline & $\begin{array}{l}\text { Weakly } \\
\text { Virulent }\end{array}$ & $\begin{array}{l}\text { Moderately } \\
\text { Virulent }\end{array}$ & $\begin{array}{l}\text { Highly } \\
\text { Virulent }\end{array}$ & \\
\hline Hydrolysis of aesculin & $2 / 19(10 \%)$ & $6 / 15(40 \%)$ & $15 / 19(79 \%)$ & $0.9944^{* *}$ \\
\hline Fermentation of L-arabinose & $7 / 19(36 \%)$ & $7 / 15(46 \%)$ & $15 / 19(79 \%)$ & 0.9129 \\
\hline Fermentation of saljcin & $1 / 19(5 \%)$ & $7 / 15(46 \%)$ & $16 / 19(84 \%)$ & $0.9995^{* k}$ \\
\hline Utilization of citrate & $19 / 19(100 \%)$ & $13 / 15(86 \%)$ & $5 / 19(26 \%)$ & 0.8780 \\
\hline Production of indole & $19 / 19(100 \%)$ & $11 / 15(73 \%)$ & $9 / 19(47 \%)$ & $0.9999^{* x:}$ \\
\hline $\mathrm{H}_{2} \mathrm{~S}$ from $2.5 \%$ peptone & $19 / 19(100 \%)$ & $7 / 15(46 \%)$ & $6 / 19(32 \%)$ & 0.9570 \\
\hline $\begin{array}{l}\text { Reddish-brown pigment in } \\
\text { tyrosine agar }\end{array}$ & $0 / 19(0 \%)$ & $1 / 15(6 \%)$ & $8 / 19(42 \%)$ & 0.8547 \\
\hline
\end{tabular}

" Coefficients of determination ( $\left.\mathrm{R}^{2}\right)$ for the relationships between the 3 virulence levels (weak, moderate and high) and bjochemical charactristics of $A$. hydrophilu isolates.

*t significantly different $p<0.05$

Table 6 : Antibiotic sensitivity of 53 A. hydrophila isolates recovered from EUS affected fish

\begin{tabular}{lll}
\hline Antibiotics & $\mu \mathrm{g} \mathrm{m} \mathrm{l}^{-1}$ & Number of sensitive isolates (\%) \\
\hline Ampicillin & 10 & $0(0 \%)$ \\
Chloramphenicol & 10,30 & $53(100 \%)$ \\
Erythromycin & 15 & $35(66 \%)$ \\
Gentamycin & 10 & $53(100 \%)$ \\
Kanamycin & 30 & $53(100 \%)$ \\
Nalidixic acid & 30 & $53(100 \%)$ \\
Nitrofurantoin & 100,300 & $53(100 \%)$ \\
Oxytetracyclin & 20,30 & $53(100 \%)$ \\
Rifampicine & 2 & $0(0 \%)$ \\
Streptomycin & 10 & $53(100 \%)$ \\
Sulphonamide & 300 & $28(53 \%)$ \\
Tetracycline & 10,30 & $53(100 \%)$ \\
Trimethoprim & 25 & $0(0 \%)$ \\
\hline
\end{tabular}


defined at $96 \%$ similarity value. Phenons are described as groups of organisms that have high degree of similarity. ${ }^{13}$ Some of the isolates of $A$. hydrophila showed atypical reactions to some of the recommended tests for the identification of $A$. hydrophila given by Popoff. ${ }^{12}$ Some of the isolates classified into phenon I, II and III showed three characteristics of A. sorbia (inability to hydrolyze aesculin, and to ferment L-arabinose and salicin). Few isolates in phenon V, VI and VII. produced reddish brown pigment in tyrosine agar though, which is a characteristic of A. salmonicida. However, the isolates grouped as phenon IV perfectly fit into the typical characteristics of $A$. hydrophila described by Popoff. ${ }^{12}$ In general, isolates recovered from the same fish showed similar characteristics, whereas variable characteristics were observed among the isolates recovered from ulcerated fish collected from different waterbodies confirming the opportunistic nature of the $A$. hydrophila strains associated with EUS.

Three biochemical characteristics namely hydrolysis of aesculin, fermentation of salicine and formation of indole were correlated with the virulence potential of the isolates. Virulence potential has also shown positive correlations with lysine decarboxylase, fermentation of arabinose, gas production and VP test."."

Antibiotic susceptibility tests show that the isolates were resistant to ampicillin, rifampicin and trimethoprim. Resistance of $A$. hydrophila isolates to ampicillin has also been observed previously. ${ }^{20}$ All the A. hydrophila isolated from EUS affected fish in the present study were $100 \%$ susceptible to 8 of the 13 antimicrobial drugs tested. Variable sensitivities were displayed for erythromycin and sulphonamide. The range of sensitivity of the isolates towards different groups of antibiotics indicates that fish sampling areas have not been previously exposed to these antibiotics.

Variable virulence potential of the isolates of $A$. hydrophila observed in the present study is in agreement with the previous reports regarding differences in virulence potential of $A$. hydrophila isolates recovered from EUS affected fish in the Philippines. ${ }^{21,22}$ In the present study, most of the isolates classified under phenons V, VI and VII were highly virulent. Isolation of highly virulent bacteria from severe lesions suggests that $A$. hydrophila does have a significant impact on the pathological progression of the lesion.

In conclusion, phenotypic.variations and range of virulence exhibited by A. hydrophila isolates recovered from ulcerated fish collected from different habitats during three consecutive outbreaks of EUS in Sri Lanka revealed that a highly virulent single specific strain of $A$. hydrophila is not primarily associated with EUS. A. hydrophila is generally considered as an opportunistic pathogen which produces diseases under stress conditions often associated with other microorganisms. Association of A. hydrophila in EUS affected fish in Sri Lanka suggests that $A$. hydrophila strains present in the aquatic environment may be 
important in the pathogenesis of EUS. Current evidence indicates that the fungus A. invadans must attach to the dermis before it can invade underlying tissue." A. hydrophila has been shown to adhere to fish cells and fish mucus and has ability to invade epithelial cells. ${ }^{2: 3}$ Cutaneous $A$. hydrophila infection may predispose fish to EUS by inducing skin lesions, which provide an entry for the fungus. EUS affected fish die due to septicaemia caused by bacteria. ${ }^{4,8}$ It is also likely that the bacteria first colonize the surface of ulcers caused by the fungus and then invade the blood stream to induce lethal septicaemia.

\section{Acknowledgement}

This research was supported by the International Foundation for Science, Sweden and the National Science Foundation of Sri Lanka.

\section{References}

1. FAO (1986). Report of the expert consultation on ulcerative fish diseases in the Asia-Pacific region. (TCP/RAS/4508). 5-9 August, FAO Regional Office for Asia and Pacific, Bangkok, Thailand

2. Lilley J. H., Phillips M. J. \& Tonguthai K. (1992). A Review of Epizootic Ulcerative Syndrome(EUS) in Asia. Aquatic Animal Health Research Institute and Network of Aquaculture Centers in Asia-Pacific, Bangkok, Thailand $73 \mathrm{pp}$.

3. Costa H. H. and Wijeyaratne M.J.S. (1989). Epidemiology of the epizootic ulcerative syndrome occurring for the first time among fish in Sri Lanka. Journal of Applied Ichthyology 1:48-52.

4. Pathiratne A., Widanapathirana G.S., \& Chandrakanthi W.H.S. (1994). Association of Aeromonas hydrophila with epizootic ulcerative syndrome (EUS) of freshwater fish in Sri Lanka. Journal of Applied Ichthyology 10: 204-208.

5. Balasuriya L.K.S. (1994). Epizootic Ulcerative Syndrome in Fish in Sri Lanka. Country Status Report. In: Proceedings of the ODA Regional Seminar on Epizootic Ulcerative Syndrome (Eds. R. J. Roberts, B. Campbell \& I.H. MacRae) pp.33-47.Aquatic Animal Health Research Institute, Bangkok, Thailand

6. Pathiratne A. \& Jayasinghe R. P. P. K. (2000). Environmental influence on occurrence of epizootic ulcerative syndrome(EUS) in freshwater fish in Bellanwila - Attidiya wetlands, Sri Lanka. Journal of Applied Ichthyology. (in press) 
7. Robert R.J., Campbell B. \& MacRae I.H. (1994). Proceedings of the ODA regional seminar on epizootic ulcerative syndrome. Aquatic Animal Health Research Institute, Bangkok, Thailand $282 \mathrm{pp}$.

8. Lilley J. H., Callinan R. B., Chinabut S., Kanchanakhan S., MacRae I. H. \& Phillips M. J. (1998). Epizootic ulcerative syndrome (EUS) technical handbook. The Aquatic Animal Health Research Institute, Bangkok, Thailand 88pp.

9. Austin B. \& Austin D. A. (1989). Methods for the microbiological examination of fish and shellfish pp. 317. Ellis Horwood Limited.

10. Shotts E.M. \& Bullock G.L. (1975). Bacterial diseases of fishes: diagnostic procedures for gram-negative pathogens. Journal of Fisheries Research Board of Canada 32: 1243-1247.

11. Cowan S. T. \& Steel K. J. (1981). Cowan and Steel's manual for the identification of medical bacteria. 2nd Edition, Cambridge University press, Cambridge.

12. Popoff M. (1984). Genus III. Aeromonas In:Bergey's manual of systematic bacteriology, Vol I (Eds. J. G. Holt \& N. R. Krieg) pp. 545-548: Williams and Wilkins, Baltimore.

13. Sneath, P. H. A. (1957). The application of computers to taxonomy. Journal of General Microbiology 17: 201-226.

14. Zar, J.H. (1974). Biostatistical analysis. Prentice Hall Inc., Englewood Cliffs, New Jersy USA.

15. Bauer A. W., Kirby W. M. M., Sherris J. C. \& M. Truck. (1966). Antibiotic susceptibility testing by a standardized single disk method. The American Journal of Clinical Pathology 45( 4): 493-496.

16. Roberts R. J. (1993). Motile aeromonad septicaemia In: Bacterial diseases of Fish ( Eds. V. Inglis, R. J. Roberts \& N. R. Bromage). pp. 143-155. Blackwell Scientific publications, London

17. Allen D. A., Austin B. \& Colwell. R. R. (1983). Numerical taxonomy of bacterial isolates associated with a freshwater fishery. Journal of General Microbiology 129:2043-2062

18. Kampfer P. \& Altwegg M. (1992). Numerical classification and identification of Aeromonas genospecies. Journal of Applied Bacteriology 72:341-351 
19. Burke V., Robinson J., Cooper M., Beaman J ., Partrige K., Peterson D. \& Gracey M. (1984). Biotyping and virulence factors in clinical and environmental Aeromonas species. Applied Environmental Microbiology 47:1146-1149

20. Ansary A., Haneef R. M., Torres J.L. \& Yadav M. (1992). Plasmids and antibiotic resistance in Aeromonas hydrophila isolated in Malaysia from healthy and diseased fish. Journal of Fish Diseases 15:191-196

21. Torres J. L., Shariff M. \& Law A. T. (1990). Identification and virulence screening of Aeromonas spp. isolated from healthy and epizootic ulcerative syndrome (EUS) infected fish. In: Proceedings of the Second Asian Fisheries Forum (Eds. R. Hirano \& I. Hanyu.) pp.663-667 Asian Fisheries Society, Manila, Philippines.

22. Torres J. L., Tajima K. \& Shariff M. (1993). Numerical taxonomy and virulence screening of Aeromonas spp. isolated from healthy and epizootic ulcerative syndrome-positive fishes. Asian Fisheries Science 6:11-22

23. Krovacek K., Faris A., Ahne W. \& Mansson I. (1987). Adhesion of Aeromonas hydrophila and Vibrio anguillarum to fish cells and to mucus coated glass slides. FEMS Microbiology Letters 42:85-89 